\title{
On formation and activity of IASS
}

\author{
A. S. Hojaev \\ Ulugh Beg Astronomical Institute, Uzbek Academy of Sciences \\ Astronomicheskaya, 33, Tashkent, 100052, Uzbekistan \\ email: hojaev@yahoo.com
}

\begin{abstract}
A brief description of International Aerospace School (IASS) is given.
Keywords. sociology of astronomy, history and philosophy of astronomy, miscellaneous
\end{abstract}

Central Asia has a remarkably wealthy and deep intellectual tradition in the sciences and was the creative intellectual capital of the world between 800 and 1600, which achieved signal breakthroughs in many fields including astronomy. They gave algebra its name, calculated the earth's diameter with unprecedented precision, wrote the books that later defined European medicine, and penned some of the world's greatest poetry (see, e.g., Starr 2015).

Present Uzbek astronomers still play a key role in scientific research collaborating with many foreign colleagues. International Aerospace School (IASS) is a unique project in the region held annually since 1989(twice a year during a few first years), i.e. active for more than quarter of a century. Academician S.Vakhidov and famous cosmonaut, general V. Djanibekov were founders of IASS . The main support is provided by Vakhidov's Youth AeroSpace Fund. At present the summer camp gathers about 50 teenage and undergraduate students over different regions of Uzbekistan, Russia, Kazakhstan, Kyrgyzstan, Ukraine, Tajikistan, Azerbaijan, Georgia, Pakistan, Malaysia, Turkey, Poland and France (since 2005), etc. They are selected based on tests of astronomy and space science, and on qualifying competition. Working languages are Uzbek, Russian, French, English. The qualified simultaneous translation of lectures and instructions is provided. During two weeks of IASS camp the invited physicists and astronomers, cosmonauts and astronauts, pilots and instructors of the airlines as well as other specialists give lectures and engage in practical exercises with IASS students in astronomy, including daily observations of the Sun and night sky observations with meniscus telescope, space research and exploration, aerospace modelling, visiting the special technical facilities like unique Large Solar Furnance in Parkent, preparation and presentation of original projects. Lectures and practice in astronomy are carried out with the generous assistance of Uranoscope Association (Paris, France). This is important that IASS gives not theoretical basics only but also practically train the students, and the hands-on training are among or within the major aims of IASS. IASS alumni become students of physics, technology, aviation universities and colleges, pilots of cosmonaut corps and national airlines,design engineers in aerospace, scientists of research institutes and teachers at universities. The 26-th IASS season was held in July-August 2015, the next one is scheduled for the same time in 2016. IASS invites students as well as lecturers and instructors from abroad to participate in the camp and take part in other IASS activities. It will appreciate any sponsor contributions. Contact e-mail is presented in affiliation line above.

\section{References}

Starr, S. F. 2015, Lost Enlightenment: Central Asia's Golden Age from the Arab Conquest to Tamerlane (Princeton University Press), $680 \mathrm{pp}$. 